EDUR • Educação em Revista. 2021; 37:e25112

DOI: http://dx.doi.org/10.1590/0102-469825112

(a) (1) https://creativecommons.org/licenses/by/4.0/

PALAVRA ABERTA

\title{
EDUCAÇÃO E PANDEMIA: OUTRAS OU REFINADAS FORMAS DE EXCLUSÃO?
}

\author{
ANA ELISA SPAOLONZI QUEIROZ ASSIS ${ }^{1 ; 2}$ \\ ORCID: https://orcid.org/0000-0003-3759-4845
}

\begin{abstract}
RESUMO: O objetivo do artigo é problematizar discursos proferidos por professores e estudantes no âmbito dos órgãos de gestão democrática educacionais públicos, enfatizando aspectos excludentes que tendem a destacar perspectivas de inovação, proatividade e/ou sucesso. Recorre-se à argumentação conceitual, de forma a explorar as categorias analíticas que emergiram desse processo especulativo, quais sejam: necessidade, tranquilidade e facilidade. A categoria discursiva de "necessidade" é sustentada tanto a partir de discursos individualistas, como "preciso me formar", quanto coletivistas: "importante fazer o que for possível". Já a categoria de "tranquilidade" vem acompanhada de um discurso que pressupõe familiaridade com as ferramentas e o modelo remoto: "é intuitivo"; "é só usar"; "sempre existiu a plataforma, todos deveriam usar e saber usar". E, por fim, a categoria da "facilidade" se pauta na generalização sem conhecimento de causa, traduzida em frases como: "mas todo mundo tem um celular hoje em dia". Conclui-se questionando a validade dos argumentos ao exasperarem fatores de exclusão em lugar de mitigá-los.
\end{abstract}

Palavras-chave: educação, direitos fundamentais, Covid-19, exclusão.

\section{EDUCATION AND PANDEMIC: OTHER OR REFINED FORMS OF EXCLUSION?}

ABSTRACT: The aim of the article is to problematize speeches made by teachers and students within the scope of public educational democratic management bodies, emphasizing exclusionary aspects that tend to highlight perspectives of innovation, proactivity, and / or success. We use conceptual argumentation to explore the analytical categories that emerged from this speculative process, namely: necessity, tranquility, and ease. The discursive category of "necessity", is sustained both from individualist speeches, as "I need to graduate", and collectivists: "important to do what is possible". The "tranquility" category, on the other hand, comes with a speech that assumes familiarity with the tools and the remote model: "it's intuitive", "just use it", "the platform has always existed, everyone should use it and know how to use it.". Finally, the "ease" category, based on generalization with no fact-base, translated into phrases such as: "but everyone has a cell phone nowadays". It concludes by questioning the validity of these arguments by exasperating exclusion factors instead of mitigating them.

Keywords: Education, Fundamental rights, Covid-19, Exclusion.

\footnotetext{
${ }^{1}$ Faculdade de Educação - Universidade Estadual de Campinas (UNICAMP). Campinas, SP, Brasil.

${ }^{2}$ Faculdade de Direito do Sul de Minas. Pouso Alegre, MG, Brasil < anaelisasqa@gmail.com> Educação em Revista |Belo Horizonte| v.37|25112|2021
} 


\section{EDUCACIÓN Y PANDEMIA: ¿OTRAS O REFINADAS FORMAS DE EXCLUSIÓN?}

RESUMEN: El objetivo del artículo es problematizar los discursos pronunciados por docentes y estudiantes en el ámbito de los órganos de gestión democrática de la educación pública, enfatizando aspectos excluyentes que tienden a resaltar perspectivas de innovación, proactividad y / o éxito. Se utilizan argumentos conceptuales para explorar las categorías analíticas que surgieron de este proceso especulativo, a saber: necesidad, tranquilidad y facilidad. La categoría discursiva de "necesidad", se sostiene tanto en discursos individualistas, como "necesito graduarme", como colectivistas: "importante hacer lo que sea posible". La categoría "tranquilidad", en cambio, viene con un discurso que asume la familiaridad con las herramientas y el modelo remoto: "es intuitivo", "solo úsala", "la plataforma siempre ha existido, todos deben usarla y saber usarla". Y finalmente, la categoría de "facilidad", que se basa en la generalización sin conocer la causa, traducida en frases como: "pero hoy día todo el mundo tiene celular". Se concluye cuestionando la validez de los argumentos exasperando los factores de exclusión en lugar de mitigarlos.

Palabras clave: Educación, Derechos fundamentales, Covid-19, Exclusión.

\section{INTRODUÇÃO}

O objetivo deste texto é problematizar discursos proferidos que compõem as discussões coletivas no âmbito dos órgãos de gestão democrática educacional, por pares e estudantes, sendo a universidade pública o local de origem dessas máximas, as quais, por não se restringirem ao contexto universitário, podem ser compartilhadas pelas discussões sobre educação pública em geral.

A ênfase é dada aos aspectos excludentes presentes nesses discursos, que tendem a justificar a existência de uma necessidade, tranquilidade e/ou facilidade em realizar a transição das atividades presenciais ao modelo remoto, em que o contexto nacional pré-pandemia é tratado como contexto instaurado pós-pandemia.

Recorre-se à argumentação conceitual, de forma a explorar as categorias analíticas que emergiram desse processo especulativo - necessidade, tranquilidade e facilidade -, evidenciando os motivos de exclusão presentes nos referidos discursos.

Para fins de discussão, é importante discorrer sobre a compreensão das categorias discursivas aqui privilegiadas. A categoria discursiva de "necessidade" é sustentada tanto a partir de discursos individualistas, como "preciso me formar", "todo mundo está fazendo", "eu posso fazer", quanto coletivistas: "é importante manter o contato com as pessoas nesse momento"; "importante fazer o necessário"; "importante fazer o que for possível"; "somos funcionários públicos, é nossa obrigação".

Já a categoria de "tranquilidade" vem acompanhada de um discurso que pressupõe familiaridade com as ferramentas, com o formato, com a existência de tempos e espaços previamente acordados: "é intuitivo"; "é só usar"; "façamos treinamento remoto das ferramentas"; "sempre existiu a plataforma, todos deveriam usar e saber usar".

E, por fim, a categoria da "facilidade" se pauta na generalização sem conhecimento de causa, traduzida em frases como: "mas todo mundo tem um celular hoje em dia".

A despeito da divisão, essas categorias dialogam intimamente, por vezes até se misturam, num encadeamento de argumentos autossuficientes. Entretanto, a categoria "facilidade" é a mais perigosa, pois demonstra desconhecimento total do contexto educacional e social brasileiro, em especial por parte de doutores que representam uma elite intelectual, já que são apenas $0,2 \%$ do total da população nacional (OCDE, 2019).

Mesmo com o destaque a uma das categorias, o problema central é: não importa por qual ângulo seja, todas essas falas são, em essência, excludentes. 


\section{EXCLUSÕES ANTES, DURANTE E DEPOIS DA PANDEMIA}

No ano de 2020, devido ao afastamento físico ${ }^{2}$, o número de lives realizadas no Instagram aumentou em 70\% (FIORE, 2020). A revista Exame obteve informações do YouTube indicando um crescimento de $4.900 \%$ na busca por conteúdos ao vivo. A reportagem ainda destaca a sobrecarga da internet relativa ao aumento de 30\%, entre fevereiro e março, do tráfego global de dados (AGRELA et. al., 2020). Ainda que o foco prioritário seja a área de entretenimento, os profissionais e as instituições de educação, sejam da educação básica ou superior, públicas ou privadas, também contribuíram para a configuração desse cenário.

Os discursos destacados, em sede de introdução, pautados em argumentos de necessidade, tranquilidade e / ou facilidade, parecem não só ter ganhado espaço e adeptos, como também demandado planejamento, que já nasce fadado ao fracasso se a compreensão de fracasso escolar engloba o exercício e a efetivação de um direito à educação excludente (ASSIS, 2012).

Exemplos dessa euforia discursiva, para além das instâncias democráticas de gestão educacional, não faltam: "Educação pós-pandemia e a urgência da transformação digital" (SATHLER, 2020); "Educação: Limites no infinito" (UNINTA, 2020); "Vetores Saudáveis: Possível Reconfiguração dos Modelos Educacionais Pós-Pandemia", em que o evento, realizado pelo Instituto de Estudos Avançados do Estado de São Paulo (IEA) juntamente com a Pró-Reitoria de Pesquisa da USP e a Academia de Ciências do Estado de São Paulo (Aciesp), reforça "a necessidade de novos modelos de educação" (BELLESA, 2020, s/p); "A graduação da Unicamp na transição para o ensino remoto emergencial: desafios, aprendizagens e perspectivas"; "A interatividade no universo do ensino remoto"; "Docência em tempos de pandemia: expectativas, perspectivas e aprendizagens"; "Trocando experiências sobre a graduação da Unicamp e Uminho em tempos de Covid-19". Estes últimos trabalhos foram realizados pelo Espaço de Apoio ao Ensino e a Aprendizagem da Universidade Estadual de Campinas (Ea2/UNICAMP, 2020).

O contexto instalado requer uma discussão mais qualificada, com o que se pretende contribuir a partir da exploração das categorias analíticas expostas a seguir.

\section{Exclusão nos Discursos de Necessidade}

Compreende-se, no presente ensaio, que os discursos de necessidade podem ser divididos entre individuais e coletivos. Quando individualizados, o elemento de exclusão educacional e social fica bastante aparente. Isso porque os discursos carregam consigo argumentos particulares relativos exclusivamente a situações referentes apenas àquele indivíduo. $\mathrm{O}$ estudante $\mathrm{X}$ quer e pode se formar, pois tem todas as condições de acesso ao modelo remoto emergencial, mas o estudante $Y$ que quer e não pode se formar, pois não tem as condições materiais mínimas de acesso ao modelo remoto emergencial?

Uma vez que rechaçar de todo o argumento individual em um ambiente democrático pode ser entendido como um ato antidemocrático, o interessante é identificar argumentos individuais que devem e que não devem ser considerados:

\footnotetext{
A escola, como instituição que tem a tarefa de promover o diálogo, a humanização do humano e a sua emancipação (ADORNO, 1998), ao pautar seus processos de gestão a partir sempre da lógica da maioria, corre sério risco de padronizar suas tomadas de decisão em procedimentos que podem ser mais expressão da violência do que da democracia, uma vez que a maioria, mesmo que fluida, quando ciente do controle que possui sobre as decisões, dificilmente abre mão de suas posições, mesmo tendo frágeis argumentos para mantê-las, pois tem, neste caso, o principal argumento: a força (SOUZA, 2009 p. 125, grifos nossos)
}

\footnotetext{
${ }^{2}$ Embora comumente usemos a expressão "distanciamento social”, opta-se aqui por utilizar a expressão "afastamento físico", com o objetivo de enfatizar a separação de corpos potencialmente transmissores do vírus, mas não das interações sociais que continuam realizando.
} 
Mesmo que Souza (2009) não identifique quais argumentos individuais devem ou não ser considerados em ambientes democráticos, sua ponderação vem ao encontro da defesa dos direitos das minorias, que não representam, seguramente, um número menor da população geral, mas certamente têm um menor número representativo nos espaços mais importantes de tomada de decisão. Ainda que a educação superior pública tenha ampliado a participação das minorias nos vestibulares, com destaque às negras e negros, logrando êxito na conquista da vaga, e, a despeito de algumas correntes teóricas pósmodernas considerarem a discussão anacrônica, considerando-a "lamentos modernistas em um mundo pós-moderno" (VIEIRA; CALDAS, 2006 p. 64), o exercício da igualdade formal é deveras recente, o que implica uma igualdade material claudica inclusive, e principalmente, na universidade pública (PIRES, 2014).

Argumentos individuais que desconsideram os contextos local, regional, global e emergencial, acabam engrossando os discursos hegemônicos, que dificultam o diálogo qualificado e compromissado com a erradicação ou diminuição de ações excludentes:

\footnotetext{
As possibilidades de superação das desigualdades sociais, reproduzidas - entre outras formas - pelo sistema de ensino, são pauta de uma ação social/coletiva, por meio da qual a educação escolar busca rever seus rumos, suas organizações. Porém, certamente a face individual dessa tarefa parece ser a mais hercúlea das ações, pois demanda a autoconsciência, a emancipação de cada um dos indivíduos (ADORNO, 1998) e, uma vez que se constata que este é um mundo que é expressão do reino das necessidades, essa se torna uma tarefa ainda mais complexa (SOUZA, 2009 p. 127).
}

O cenário se complica quando tais discursos são oriundos de estudantes de cursos de licenciaturas, como a pedagogia, pois nos deixam alertas sobre qual é a concepção de educação que paira na mente desses futuros professores.

Quando são discursos que apelam para o coletivo, acabam tendendo para a proteção de um grupo que seria prejudicado, pois, se existem alguns que podem, por que não fazer com eles? A tentativa da aplicação de um discurso lógico que vise elemento agregador, resta prejudicado em essência, uma vez que a ideia em si já desconstrói qualquer tentativa de pregar senso de coletividade. De acordo com Souza (2009), tomando como base Touraine, a convergência entre individual e coletivo precisa ocorrer para que haja "combinação entre a unidade e a diversidade, entre a integração e a liberdade na vida social e política" (SOUZA, 2009, p. 131).

Mesmo quando se trata de um representante, na democracia, a despeito de ter sido eleito por um determinado grupo, uma vez parte daquele conjunto, ele deve pensar esse mesmo grupo em consonância com o conjunto, fugindo da lógica falaciosa da maioria enquanto promotora de situações homogêneas perfeitas a toda e qualquer diversidade (SOUZA, 2009).

\section{Exclusão nos Discursos de Tranquilidade}

Os discursos de tranquilidade acabam ignorando diversas fronteiras muito bem traduzidas por Nora Krawczyk (2020) num texto intitulado As falácias da EAD se alastram com (e como) o Covid19. Destaco aqui três delas, as quais dialogam diretamente com a tranquilidade aparente nos discursos para continuidade das aulas, como se tentassem resgatar aquela imagem de super-heroína da educação que tanto lutamos para desconstruir (BRANDÃO, 2007).

"Falácia 1: misturar situações de exceção com proposta político educacional" (KRAWCZYK, 2020, s/p). Ainda que possa haver discordância no que tange ao posicionamento de faculdades de ciências sociais e humanas - ponderando a suspensão das aulas "durante um ou dois meses seria menos grave que as oferecer nas condições atuais, e que poderiam ser recuperadas com a volta à escola" (KRAWCZYK, 2020, s/p) -, o que em muitas delas não ocorreu, inclusive na faculdade onde a professora é vinculada, mantendo as atividades sem ponderação de suspensão ${ }^{3}$, a autora tem razão ao pontuar que "teremos o desafio de encontrar estratégias que não aprofundem as desigualdades já

${ }^{3}$ Vide documentos Congregação em <www.fe.unicamp.br>. 
existentes, nem a dificuldade de conectividade de grupos significativos de alunos" (KRAWCZYK, 2020, $\mathrm{s} / \mathrm{p})$.

Além de nem todos estarem familiarizados com o formato remoto, não têm os tempos e espaços necessários para uma transição imediata, pois a vida de todos também mudou, e não apenas a organização dos trabalhos. Se antes um computador - para aqueles que o possuíam - era suficiente, em uma casa com dois adultos e duas crianças, já não é mais: cada um terá necessidade de um, em seus respectivos horários, para atender às demandas de trabalho, escola e socialização. Como adquirir, de imediato, mais três computadores? Como aumentar, de imediato, o pacote de dados da internet? Como arranjar, na casa, espaço adequado para trabalhos e estudos individualizados, já que a inexistência do silêncio com as video calls impede que uma mesa de jantar, quando caso ela exista, seja simultaneamente utilizada por todos?

Afora questões materiais e organizacionais, também existem as pessoais: como se concentrar quando há medo do desconhecido? Há uma redistribuição de tarefas entre aqueles que vivem na casa? E a preocupação com quem não pode realizar trabalho remoto? Como atender diferentes demandas simultaneamente?

Independentemente do resultado, é preciso um tempo para planejar. E planejar pensando no contexto emergencial e não em diretrizes para um novo formato de educação, sustentando a ideia de uma política educacional inovadora que incorpora de vez o mundo digital no cotidiano escolar.

Não se defende aqui uma parada total. Um laissez faire. Mas pondera-se que, talvez, o tempo em que as coisas tenham sido feitas, utilizado de forma atropelada na ânsia de atender discursos de necessidade, poderia ter sido utilizado para um planejamento. Pausa para planejar. Algo que as escolas, em geral, não conhecem há muito tempo: "Ademais, a cultura do planejamento educacional nos sistemas educativos depende da manutenção de uma política [...] em um tempo mais longo e legalmente instituído na gestão educacional como forma de construir e fortalecer a autonomia dos sistemas educacionais do País" (FONSECA et. al., 2020 p. 15).

O planejamento é instrumento essencial (BRYAN; ASSIS; PALMEN, 2016). No contexto de pandemia, faz-se ainda mais urgente. Primeiro, porque seria possível pensar formas em que não se perdesse o tempo mencionado pelos discursos de necessidade individual. Luiz Carlos de Freitas (2020, s/p) fez um exercício, em abril de 2020, propondo "Suspender as avaliações e unir os anos 20 e 21 ". A sugestão do professor, apesar de direcionar-se para a educação básica, tendo o artigo 23 da Lei de Diretrizes e Bases da Educação Nacional como suporte (Lei n. ${ }^{\circ} 9.394 / 96$ ), pode ser pensada para o ensino superior, e deveria auxiliar as instituições de educação básica nesse contexto fazendo convergir ensinopesquisa-extensão - muitas são as dificuldades desse diálogo, mas, certamente, uma delas é de responsabilidade da própria universidade quando não se dá o tempo de planejar. Em segundo lugar, não podemos garantir que não passaremos pelo mesmo problema em outro momento, sendo bom ter um plano de emergência.

"Falácia 2: Misturar EAD com uso de recursos tecnológicos" (KRAWCZYK, 2020, s/p). Tecnologia é uma dentre as diversas ferramentas para realização da educação a distância (EaD), mas não é condição dela. Figueiredo (2019) aponta vários autores conceituando educação a distância e destaca que “a 'separação física' entre professor e aluno é vista como característica marcante e determinada como principal definição da EAD” (FIGUEIREDO, 2019, p. 17) e não a tecnologia, restritivamente a internet, como se quer crer e propagar.

"Falácia 6: O EAD não tem nada a ver com a saúde dos estudantes e docentes" (KRAWCZYK, 2020, s/p). À época em que o texto da autora foi escrito, o Ministério Público do Trabalho (MPT) ainda não havia publicado a Nota Técnica - GT COVID 19, 11/2020, de 17 de junho de 2020.

Entendida aqui como uma legislação lato sensu (ASSIS, 2012), ou seja, que mesmo não sendo oriunda do Poder Legislativo possui força de lei, a nota técnica emitida pelo MPT vem ao encontro da desmistificação da falácia 6 , pois realiza nove considerações e 26 indicações "na defesa da saúde e demais direitos fundamentais de professoras e professores quanto ao trabalho por meio de plataformas virtuais e/ou em home office durante o período da pandemia da doença infecciosa COVID-19" (MPT, 2020, p. 1). Dessas, destacam-se: 
$[\ldots]$

3- OBSERVAR os parâmetros de ergonomia física e condições de trabalho previstos na Norma Regulamentadora 17, Portaria MTb 3214, de 8 de junho de 1978, em especial quanto aos equipamentos, mesas, cadeiras, a postura física, oferecendo ou reembolsando os valores dos bens necessários à garantia da integridade física;

4- OBSERVAR os parâmetros da ergonomia organizacional, principalmente aqueles que levem em consideração as normas específicas de produção, as operações a serem realizadas, as exigências de tempo, a determinação do conteúdo de tempo, o ritmo de trabalho e conteúdo das tarefas;

[...]

8- ADEQUAR, devido ao maior desgaste psicossomático da ministração de aulas por meios virtuais, a distribuição das atividades e dos tempos de trabalho;

9- INCENTIVAR o respectivo aumento dos intervalos para repouso, seja na extensão destes ou na quantidade; (MPT, 2020 p. 4-5).

$[\ldots]$

21- ADOTAR modelos de etiqueta digital em que se oriente alunas(os), responsáveis, supervisoras(es) e diretoras(es), com especificação de horários para atendimento virtual da demanda, assegurando os repousos legais, o direito à desconexão do corpo docente e a compatibilidade entre a vida familiar e profissional;

$[\ldots]$

23- ADOTAR modelos de etiqueta digital em que se oriente alunas(os), responsáveis e supervisoras(es) sobre o respeito à liberdade de expressão e de cátedra, bem como a proibição de atos de intimidação sistemática (assédio moral, bullying) no ambiente pedagógico virtual, seja verbal, moral, sexual, social, psicológico, físico, material e virtual, que podem se caracterizar pela presença do orientador pedagógico ou coordenador sem o prévio conhecimento do professor ou professora, por insultos pessoais, comentários sistemáticos e apelidos pejorativos, ameaças por quais meios, expressões preconceituosas, pilhérias, "memes". (MPT, 2020 p. 7).

O documento elaborado pelo MPT demonstra que não se trata de uma adequação, de uma atividade imediatista que pode institucionalizar os improvisos. Existem consequências das mais diversas ordens, inclusive corporais e psicológicas para docentes e discentes.

Nesse sentido, não se trata de um cenário tranquilo. Não há tranquilidade, pois não há planejamento que vá ao encontro de uma gestão democrática que não enfatize discursos excludentes. Não há tranquilidade, uma vez que é preciso desmascarar relações aparentemente comuns entre EaD e internet. Não há tranquilidade, pois não se trata apenas de abrir um note em uma mesa e dialogar remotamente.

\section{Exclusão nos Discursos de Facilidade}

Finalmente, as exclusões presentes nos discursos de facilidade, que, diante dos outros dois, demonstra total desconhecimento da situação antes da pandemia no país por parte daqueles que desses discursos se valem. Há uma generalização descompromissada com a realidade nos discursos proferidos nesta categoria. É como se tudo estivesse à mão, basta pegar. E, mesmo que estivessem, por si sós, não bastariam

Se é possível generalizar algo neste momento, talvez seja que o planeta Terra está lidando com a pandemia da COVID-19, mas cada localidade o faz à sua maneira, considerando aportes estruturais, organizacionais, econômicos, sociais e até conceituais. Considerando novamente o trabalho de Krawczyk (2020), ao apontar a "Falácia 4: em 'todo o mundo isso está acontecendo", a autora questiona: "Para começar, quando se diz todo o mundo, não se diz nada. Que país? Que universidade? Como funciona? Por favor, vamos falar sério. Quais são as tendências hegemônicas hoje em educação?" (KRAWCZYK, 2020, s/p).

Também a nota técnica do MPT (2020) combate as generalizações de discursos de facilidade:

5- GARANTIR ao corpo de docentes e discentes com deficiência acesso a todos os equipamentos, recursos de tecnologia assistiva e acessibilidade para que tenham condições plenas para aplicar e/ou acompanhar métodos e técnicas pedagógicas, bem 
como acesso, entre outros recursos, a intérprete da Libras, legenda oculta e audiodescrição, quando necessários. (MPT, 2020 p. 4).

As diferenças sociais foram criadas pela pandemia? As deficiências? As pessoas com deficiência já eram atendidas adequadamente? Não havia diferença entre os países e seus sistemas de saúde antes da pandemia? O Brasil é um país em que todos têm acesso à internet, possuem celulares e notebooks? O Brasil é um país em que todos em idade escolar estão na escola?

É como se os problemas fossem criados pela pandemia quando, em verdade, isso só demonstra o quanto eles sofrem uma tentativa de serem naturalizados. Eles estavam lá, empurrados para debaixo de vários tapetes da mente de muitos mais do que se gostaria de admitir. $O$ ensino superior não é universalizado. A parca ampliação de acesso para atender às diversidades também não foi um processo tranquilo. Discussões sobre acesso e permanência movimentam a educação:

Visando melhorar os índices de escolarização e democratização do Ensino Superior,
diferentes políticas públicas vêm contribuindo para o ingresso e a permanência de
segmentos sociais historicamente excluídos do ambiente universitário. [...] Embora a
presença de segmentos dos meios populares nas instituições de Ensino Superior tenha
aumentado significativamente, a democratização está longe de se concretizar e, para que
se torne de fato uma realidade, não pode se limitar somente ao acesso nesse nível de
ensino (SOUZA, 2016). Mas é inegável que os estudantes provenientes dos est ratos
populares socialmente desfavorecidos lograram uma conquista importante por meio da
Lei no ${ }^{\circ}$. 12.711 (BRASIL, 2012), que tornou obrigatória a reserva de vagas para pessoas
oriundas de escolas públicas, com baixa renda, negros e indígenas em todos os cursos
ministrados nas IES federais (PENA et.al., 2020, p.28)

Esqueceu-se como era o Brasil antes da pandemia? Ou se assumiu que as igualdades formais e materiais já haviam sido conquistas em suas totalidades?

No que tange ao direito à educação, para nos atermos a um recorte mais recente, desde 1988, com a Constituição Federal, temos buscado tornar realidade a primeira parte do artigo 205: "A educação, direito de todos" (BRASIL, 1988). Em junho de 2019, a agência IBGE Notícias indicou que: "O acesso à educação básica obrigatória pela Constituição no país, [...] cresceu de 45,0\% para 47,4\% da população de 25 anos ou mais, nesse período de 2 anos. No entanto, variava de 53,6\%, no Sudeste a 38,9\% no Nordeste. E era maior entre brancos (55,8\%) do que pretos ou pardos (40,3\%)" (IBGE, 2019, s/p). Sobre a educação superior, que não faz parte de um direito público subjetivo ${ }^{4}$, ou seja, ainda precisa conquistar espaço no escopo dos artigos 205 e 208, temos que a "taxa de escolarização de jovens de 18 a 24 anos era de 32,7\%, mas apenas 25,2\% estavam no curso superior", destes, $77 \%$ estavam em entidades privadas (IBGE, 2019, s/p).

Em 2014, foi promulgada a Lei n. ${ }^{\circ} 12.965$, o Marco Civil da Internet, que, em seu artigo $4^{\circ}$, disciplina o uso da internet no Brasil, promovendo o direito de acesso à internet a todos e a adesão a padrões tecnológicos abertos que permitam a comunicação, a acessibilidade e a interoperabilidade entre aplicações e bases de dados, entre outros. Destaca, no artigo $7^{\circ}$, que o acesso à internet é essencial ao exercício da cidadania e assegura diversos direitos ao usuário, com base nessa premissa.

Assim como a educação é direito de todos, mas tem dificuldades em abarcar essa totalidade, o mesmo ocorre com a internet. De acordo com a Diretoria de Pesquisas, Coordenação de Trabalho e Rendimento, na Pesquisa Nacional por Amostra de Domicílios Contínua, promovida pelo IBGE, em 2017, apenas $74,9 \%$ dos domicílios no Brasil utilizavam a internet. No Sudeste, a taxa urbana era de $83,1 \%$, e a rural de $51,2 \%$, totalizando $81,1 \%$. Já no Nordeste os números eram, respectivamente: $73 \%, 35,8 \%$ e $64,0 \%$.

Dos domicílios em que não havia utilização da internet, dos motivos que se destacam estão: "Serviço de acesso à internet era caro", acusando 22,8\% na zona urbana e 20,4\% na zona rural brasileiras, e "Nenhum morador sabia usar a Internet", com taxas de 24,6\% na zona rural e 30,6\% na zona urbana (IBGE, 2017).

\footnotetext{
${ }^{4}$ Ver Duarte (2004) e Assis (2012).
} 
Quando os dados focam nas pessoas que utilizaram a internet, o cenário é mais alarmante. Em 2016, no Brasil, o número era de 64,7\%, com menor taxa no Nordeste $(52,3 \%$ ) e a maior taxa no Sudoeste (72,3\%). Em 2017, a mudança não é tão grande, os números eram, respectivamente: 69,8\%, $58,4 \%$ e $76,5 \%$ (IBGE, 2017).

Não bastasse a dificuldade encontrada no acesso à educação e à internet, há ainda que superar a forma de acesso. Dos equipamentos utilizados para acessar a internet no domicílio, em 2017: 98,7\% eram telefones móveis celulares; 52,3\% microcomputadores (com uma queda referente à 2016, quando eram 57,8\%); e 15,5\% tablets (também com uma queda referente à 2016, quando o percentual era de 17,8\%) (IBGE, 2017).

Os diversos levantamentos realizados entre estudantes da graduação indicam que parcela significativa dos estudantes está entre esses bolsões de exclusão: não tem acesso à internet em suas casas; não tem computadores; tem celulares, mas com pacotes baratos que não permitem assistir todas as aulas da semana via streaming ${ }^{5}$. E, acaso tenham celulares e dados, pergunta-se: É possível elaborar um texto no celular? É possível interagir na aula remota pelo celular?

A despeito de ações, como a da Unicamp, em oferecer equipamentos, simcards, entre outros, constata-se que as medidas foram insuficientes para garantir minimamente a presença e interação dos estudantes nas aulas adaptadas.

\section{CONSIDERAÇÕES FINAIS}

Como valer-se, nesse contexto, de discursos de necessidade, tranquilidade e/ou facilidade? Trata-se de um novo tipo de exclusão?

O momento atual tem permitido desconsiderar a realidade, que encontra cada vez mais dificuldade em se fazer entender ou em ser compreendida - independente da corrente teórica que se use para com ela dialogar. É um momento em que as ciências, em especial as humanas, estão rodeadas de discursos de que elas para nada servem.

Muitos já fizeram apontamentos semelhantes aos aqui trabalhados, inclusive antes deste momento mais complicado e grave, considerando a quantidade de pessoas que morrem diariamente: são, no momento de finalização do texto, 422.000 mortes. Se um minuto de silêncio fosse dedicado para cada um, seriam aproximadamente 293 dias sem falar.

Ao alcance estão: o conhecimento, o estudo, a familiaridade com os objetos de trabalho, para a realização de análises que poderiam minimizar o impacto deste momento. Se as Ciências Biológicas e Exatas estão na linha de frente do combate à Covid-19, é indubitável que o suporte fica por conta das Ciências Humanas, são elas que discutem o contexto e apontam questões a ser consideradas em planejamentos para a manutenção das vidas e da sociedade, desmascarando os discursos excludentes e também os economicamente duais: trabalhar ou morrer? Ainda que não sejam as respostas que se quer, são as respostas da ciência, e, com elas, é possível construir o cenário que se deseja.

\section{REFERÊNCIAS}

AGRELA, L; CURY, M.E.; VITORIO, T. Na quarentena, o mundo virou uma live. In: Exame, 23 Abril 2020. Disponível em: <https://exame.com/revista-exame/o-mundo-e-uma-live/>. Acesso em: 22 jul. 2020.

ASSIS, A.E.S.Q. Direito à Educação e diálogo entre poderes. Tese de Doutorado. Faculdade de Educação da Universidade Estadual de Campinas (FE/UNICAMP), 2012.

BRYAN, N. A. P.; ASSIS, A.E.S.Q.; PALMEN, S. H. C. Planejamento e Avaliação: "Planejamento e Avaliação Educacional" no contexto formativo do Curso de Especialização em Gestão Educacional -

\footnotetext{
${ }^{5}$ De acordo com o Netflix, "Ao assistir às séries e filmes da Netflix, você usa cerca de 1 GB de dados por hora em cada transmissão de vídeos com definição padrão e até $3 \mathrm{~GB}$ por hora em cada vídeo de alta definição. O download e a transmissão consomem quantidades semelhantes de dados" (NETFLIX, 2020, s/p). 
CEGE. In: MAZZA, Débora (Org.). Relação entre a Universidade Pública e a Rede Municipal de Educação. 1ed.Curitiba: Appris, 2016, v. 1, p. 87-106.

BELLESA, M. Pandemia reforça necessidade de novos modelos de educação, dizem pesquisadores. In: IEA/USP, 18 Maio 2020. Disponível em: <http://www.iea.usp.br/noticias/covid-19-leva-a-repensara-educacao >. Acesso em: 22 jul. 2020.

BRANDÃO, C.R.. O que é educação. São Paulo: Brasiliense, 2007.

BRASIL, Constituição da República Federativa do Brasil de 1988. Disponível em: $<$ http://www.planalto.gov.br/ccivil_03/constituicao/constituicaocompilado.htm>. Acesso em: 22 jul. 2020 .

BRASIL, Estabelece princípios, garantias, direitos e deveres para o uso da Internet no Brasil. Lei n. ${ }^{\circ} \mathbf{1 2 . 9 6 5}$ de 2014. Disponível em: <http://www.planalto.gov.br/ccivil_03/_ato20112014/2014/lei/112965.htm>. Acesso em: 22 jul. 2020.

BRASIL, Lei de Diretrizes e Bases da Educação Nacional, Lei n. ${ }^{\mathbf{0}} 9.394$ de 1996. Disponível em: <http://www.planalto.gov.br/ccivil_03/leis/19394.htm>. Acesso em: 22 jul. 2020.

DUARTE, C.S.. Direito público subjetivo e políticas educacionais. In: São Paulo Perspec., São Paulo, v. 18, n. 2, p. 113-118, jun. 2004.

Ea2/UNICAMP. Eventos. 2020. Disponível em: <https://www.ea2.unicamp.br/eventos/>. Acesso em: 22 jul. 2020.

FIGUEIREDO, S.B. Percurso histórico da educação a distância (EAD) na formação de professores. Nova Paideia, Revista Interdisciplinar em Educação e Pesquisa Brasília/DF, v. 1, n. 2. p. 15-26, 2019.

FIORE, M. Com pandemia, Instagram vê uso de lives crescer 70\% durante mês de março. In: B9, 16 Abril. 2020. Disponível em: <https://www.b9.com.br/124805/com-pandemia-instagram-ve-uso-delives-crescer-70-durante-mes-de-marco/>. Acesso em: 22 jul. 2020.

FONSECA, M.; FERREIRA, E.B.; SCAFF, E.A.S.. Planejamento e gestão educacional no Brasil: hegemonia governamental e construção da autonomia local. Educ. Rev., Curitiba, v. 36, e69766, 2020.

FREITAS, L.C. Suspender as avaliações e unir os anos 20 e 21. In: Avaliação Educacional - Blog do Freitas, 02 Abril 2020. Disponível em: < https://avaliacaoeducacional.com/2020/04/02/suspender-asavaliacoes-e-unir-os-anos-20-e-21/>. Acesso em: 22 jul. 2020.

IBGE. PNAD Contínua 2018: educação avança no país, mas desigualdades raciais e por região persistem. Disponível em: <https://agenciadenoticias.ibge.gov.br/agencia-sala-de-imprensa/2013agencia-de-noticias/releases/24857-pnad-continua-2018-educacao-avanca-no-pais-mas-desigualdadesraciais-e-por-regiao-persistem>. Acesso em: 22 jul. 2020.

KRAWCZYK, N. As falácias da EAD se alastram com (e como) o Covid19. In: ADUnicamp, 14 Junho 2020. Disponível em: <http://adunicamp.org.br/novosite/as-falacias-da-ead-se-alastram-com-e-comoo-covid19/>. Acesso em: 22 jul. 2020.

MINISTÉRIO PÚBLICO DO TRABALHO. Nota Técnica - GT COVID 19 - 11/2020 de 17 de junho de 2020. Disponível em: <https://mpt.mp.br/pgt/noticias/nota-tecnica-n-17-sobre-trabalhoremoto-gt-covid-19-e-gt-nanotecnologia-1.pdf>. Acesso em 08 mar. 2021. 
OCDE, Education at a Glance 2019: OECD Indicators. Germany: OECDPublishing. 2019.

NETFLIX, Ajuda. Disponível em: <https://help.netflix.com/>. Acesso em: 22 jul. 2020.

PENA, M.A.C.; MATOS, D.A.S.; COUTRIM, R.M.E.. Percurso de estudantes cotistas: ingresso, permanência e oportunidades no ensino superior. In: Avaliação (Campinas), Sorocaba, v. 25, n. 1, p. $27-$ 51, abr. 2020.

PIRES, M.F.C. Docentes negros na universidade pública brasileira: docência e pesquisa como resistência e luta. Tese de Doutorado. Faculdade de Educação da Universidade Estadual de Campinas (FE/UNICAMP). 2014.

SATHLER, L. Educação pós-pandemia e a urgência da transformação digital. In: IGTI Blog, Abril/Maio, 2020. Disponível em: <https://www.igti.com.br/blog/urgencia-da-transformacao-digitalna-educacao/>. Acesso em: 22 jul. 2020.

SOUZA, A.R. Explorando e construindo um conceito de gestão escolar democrática. In: Educação em Revista, Belo Horizonte v.25 n.03, p.123-140, dez. 2009.

UNINTA. Diretoria de Inovação Educacional promove ciclo de debates sobre educação pós pandemia. 2020. Disponível em: <https://ead.uninta.edu.br/noticias/diretoria-de-inovacaoeducacional-promove-ciclo-de-debates-sobre-educacao-pos-pandemia/>. Acesso em: 22 jul. 2020.

VIEIRA, M.M.F.; CALDAS, M.P. Teoria Crítica e Pós-Modernismo: principais alternativas à hegemonia funcionalista. In: ERA, vol. 46, n.01, 2006 p. 59-70.

Submetido: 01/09/2020

Aprovado: $30 / 11 / 2020$ 